\title{
A retrospective study on the epidemiological and clinical characteristics of SARS-CoV-2 infection among the affected pediatric population attending a tertiary care hospital in Eastern India
}

\author{
Tanusri Biswas ${ }^{1}$, Nabamita Chaudhury ${ }^{2}$, Raston Mondal ${ }^{3}$, Aroni Chatterjee ${ }^{4}$, \\ Saswati Chattopadhyay ${ }^{5}$
}

${ }^{1}$ Associate Professor and Head, ${ }^{2}$ Assistant Professor, ${ }^{4}$ Scientist B, (Non-Medical), Virus Research and Diagnostic Laboratory, ${ }^{5}$ Associate Professor, Department of Microbiology, ${ }^{3}$ Associate Professor, Department of Community Medicine, Burdwan Medical College, Burdwan, West Bengal, India

Background: Novel coronavirus infections cause major morbidity and mortality globally in the all age groups, including the pediatric population. Viral respiratory infections in children may act as a source of infection especially those with asymptomatic SARS-CoV-2 infections. Aims and Objectives: The aim is to analyze the SARS-CoV-2 characteristics in pediatric age group. Materials and Methods: Ninety seven children neonate to 5 years age tested positive by RT-PCR were included in the study. Detailed data on socio-demography, epidemiology, clinical characteristics, laboratory findings, comorbidities, management, and outcome of the study population were collected. Results: Sex distribution showed $47(48.4 \%)$ male and $50(51.5 \%)$ female. Among these 97, 5 children $(5.1 \%)$ were $<28$ days of age, 30 children were $(31 \%)$ neonate to infant age, and 62 children were $(63.9 \%)$ above 1 year but $<5$ years of age. The group was divided into two---one with 56 children $(57.7 \%)$ who were discharged, $2^{\text {nd }}$ with $41(42.3 \%)$ hospitalized children. $1^{\text {st }}$ group was asymptomatic $(64.3 \%) /$ mildly symptomatic $(35.7 \%)$. In $2^{\text {nd }}$ group $36.5 \%$ were moderately symptomatic, $29.2 \%$ were with severe complications, and $34.3 \%$ of children were critical--22 (52.6\%) required PICU admission-- 17 children (41.4\%) required mechanical ventilation and 36 (87.8\%) required respiratory support. Conclusion: Reports state that COVID-19 infection is mild in the pediatric population but our findings suggest that some children can develop severe/ critical infection requiring hospitalization, respiratory support, and mechanical ventilation.

\section{Access this article online}

\section{Website:}

http://nepjol.info/index.php/AJMS

DOI: 10.3126/ajms.v13i2.41891

E-ISSN: 2091-0576

P-ISSN: 2467-9100

Copyright (c) 2022 Asian Journal of Medical Sciences

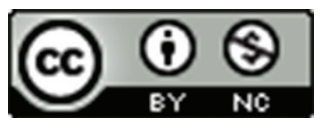

This work is licensed under a Creative Commons Attribution-NonCommercial 4.0 International License.

Key words: COVID-19; Disease severity; Inflammation; Pediatric population;

Retrospective study

\section{INTRODUCTION}

COVID-19 infection is caused by the severe acute respiratory syndrome coronavirus-2 (SARS-CoV-2) virus, a beta virus family Coronaviridae ${ }^{1}$, has high lethality and transmissibility affecting people all age groups. ${ }^{2}$ Surprisingly, children are affected in very small proportion (1-10\% positive cases worldwide). ${ }^{3}$ Reviews have described mild to moderate illness in children with full recovery in 1-3 weeks. ${ }^{4}$ However, children may not show any signs of infection, delaying its diagnosis, leading to complications and community spread. ${ }^{5}$ As the risk of intrauterine transmission is low, close contact with a source is the probably the cause of positive results in neonates. ${ }^{6,7}$ This retrospective study has been designed to lay emphasis on the understanding of different socio-demographic 
and clinical risk factors associated with COVID positive children in and around Burdwan from May 2020 to December 2020.

\section{Aims and objectives}

The aim is to analyze the different socio-demographic and clinical risk factors affecting SARS-COV-2 infection in the pediatric age group.

\section{MATERIALS AND METHODS}

\section{Patient selection}

A retrospective study was conducted in a tertiary care COVID referral hospital at Burdwan town of West Bengal with all children and newborns attending its outpatients department for COVID testing for 8 months--May 2020 to December 2020. A total of 97 children from age $<1$ month to 5 years who were tested COVID-19 positive by RT-PCR at Burdwan Medical College during the span of this period were included in the study.

\section{Sample collection}

Nasopharyngeal and oropharyngeal swabs were collected into VTMs and transported immediately to the COVID-19 referral laboratory of this institution for RT-PCR test.

\section{Data collection}

Detailed data on socio-demography, epidemiology, clinical characteristics, laboratory findings, co-morbidities, management, and outcome of our study population were collected by communicating with the guardians of the patients and also from the available medical records. All data were recorded in a pre-piloted health counseling form. Data of age groups and disease severity were extracted wherever available either from the form or from discussion with the guardians. Disease severity was classified as per the national guidelines and as discussed in Table 1. Symptomatic analysis of the patients were done and recorded in the health counseling form.

\section{Data extraction}

We recorded whether fever, cough, cold, sore throat, respiratory distress, or skin manifestations were present. For diagnosis of hyper inflammatory Syndrome/PIMS-TS we followed the diagnostic criteria as published by the World Health Organization. In patients with severe disease requiring admission in the hospital, the following data were collected-admission in pediatric intensive care units (PICUs), requirement of mechanical ventilation, presence of hypoxia (oxygen saturation $<92 \%$ ) and diagnosis of multi-organ failure.

\section{Ethical considerations}

For the study, permission from the Institutional Ethics Committee (IEC) of Burdwan Medical College and Hospital was taken (BMC/IEC/133, dated March 15, 2021). Our study included reports of all clinical examination, medical questionnaires, personal, and family history of the patients as provided by the patients/guardian of the patients.

\section{Data analysis}

Statistical analysis by Fisher exact test, or Mantel-Haenszel correction was done to determine if there was any association between different variables. Odds ratios with confidence intervals of $95 \%$ were calculated. Data were analyzed with SPSS v16.0 (Table 1).

\section{RESULTS}

A total of 97 COVID positive children who attended the outdoor unit of Burdwan Medical College and Hospital during May 2020 to December 2020 were selected for this study. Distribution by sex showed that $47(48.4 \%)$ were male and $50(51.5 \%)$ were female (OR 1.47, 95\% CI 1.02-3.18, $\mathrm{P}=0.47)$. Among these 97, $5(5.1 \%)$ were $<28$ days of age,

\section{Table 1: Criteria for predicting disease severity}

Asymptomatic 1. Signs or symptoms absent.

2. Chest X-ray normal

3. No other suggestive condition present.

Mild 1. Symptoms of upper respiratory tract infection--cough, sore throat, nasal congestion, malaise and headache with fever but no breathlessness (normal saturation).

2. Chest X-ray showing no signs of pneumonia.

1. Dyspnea, fever, cough, and $\mathrm{SpO}_{2}<94 \%$; respiratory rate $<24 / \mathrm{min}$

2. Increased respiratory rate in<2 months-- $\geq 60 / \mathrm{min}$; 2-11 months-- $\geq 50 / \mathrm{min} ; 1-5$ years-- $\geq 40 / \mathrm{min}$.

Severe 1. Oxygen saturation $\mathrm{SpO}_{2}<90 \%$

2. Signs of severe respiratory distress (apnea, gasping, and head nodding)

3. Child with severe cough/respiratory distress with at least one of the following---central cyanosis, grunting, and chest in-drawing.

4. Signs of pneumonia with any of the following---extreme lassitude, lethargy, convulsions, or unconsciousness.

5. Signs of pneumonia--chest in-drawing, increased respiratory rate-- $<2$ months $\geq 60$; $2-11$ months $\geq 50 ; 1-5$ years $\geq 40$.

6 . Need for any respiratory support

Critical 1. Patient in intensive care unit with acute respiratory distress syndrome.

2. Altered mental state; bradycardia or tachycardia (HR 160 bpm in infants and HR $150 \mathrm{bpm}$ in children); prolonged capillary refill (>2 s) or weak pulse; tachypnea; mottled or cool skin; petechial or purpuric rash; high lactate level; reduced urine output; hyperthermia; or hypothermia

3. Multi-organ failure

4. Shock, encephalopathy, myocardial injury coagulation dysfunction, features of acute renal failure. 
$30(31 \%)$ were between neonate to infancy, and $62(63.9 \%)$ were above 1 year to $<5$ years of age. The total group was divided into two sub-groups, first group with 56 children $(57.7 \%)$ who were discharged at home while the second group with $41(42.3 \%)$ children who were hospitalized. About $53.6 \%$ children belonging to the discharged group were male whereas in case of the hospitalized group the male prevalence was less, $41.4 \%$. About $91 \%$ and $90.2 \%$ of the children were of Bengali ethnic origin among the discharged and hospitalized groups, respectively. Among the discharged group, $33(58.9 \%)$ children had at least one SARS-CoV-2 infected family member, whereas among the hospitalized group, $25(60.9 \%)$ children had an infected family member. The mean+SD for the $\mathrm{Ct}$ values (in real time PCR for SARS-CoV-2 RNA) of children belonging to the discharged and hospitalized groups were $25.6+2.7$ and $23.8+3.2$, respectively. $12(21.5 \%)$ children belonging to the discharged group and $13(31.7 \%)$ children belonging to the hospitalized group had co-morbidities such as cardiac, renal, respiratory, and neuro-muscular diseases. 22 (52.6\%) of the hospitalized children required PICU admission, $17(41.4 \%)$ of them required mechanical ventilation, and $36(87.8 \%)$ hospitalized children required respiratory support. CT scan infective changes including ground glass opacity and focal consolidation were observed in $10.7 \%$ of the discharged patients and in $65.8 \%$ of the hospitalized patients. Most children belonging to the discharged group were asymptomatic $(64.3 \%)$ and the rest $35.7 \%$ were mildly symptomatic. Among the hospitalized children $36.5 \%$ were moderately symptomatic, $29.2 \%$ presented severe complications and $34.3 \%$ had a critical presentation. The mean CRP value was significantly higher in case of the hospitalized children compared to those who were discharged. The mean D-Dimer and ESR values were more or less similar for both the groups. Leukopenia was observed in case of $19.6 \%$ of the discharged children and $56.1 \%$ of the hospitalized children. Lymphopenia was observed in $12.5 \%$ of the discharged children and $29.2 \%$ among those hospitalized. Only one child out of the 56 children discharged and two children out of those 41 children hospitalized died during the course of this study. The detailed analysis is presented in Table 2 .

Among the discharged group with 56 children, fever was recorded in 16 children $(28.5 \%)$, sore throat among $12(21.4 \%)$, body ache among $10(17.8 \%)$, dyspnea among $9(16.1 \%)$, headache among $4(7.1 \%)$, vomiting among $8(14.3 \%)$, diarrhea among $5(8.9 \%)$, dry cough among $17(30.3 \%)$, thoracic pain among $3(5.35 \%)$, febrile convulsions among $6(10.7 \%)$, respiratory distress among $8(14.3 \%)$, otitis among $3(5.35 \%)$, muscle pain among 11 (19.6\%), joint pain among 7 (12.5\%), and rhinorrhea among 12 (21.4\%). Two children were hypoxemic at presentation. Among children with vomiting, one had blood mixed vomiting.
Among the hospitalized group with 41 children, 23 (56.1\%) children reported fever and $15(36.5 \%)$ reported sore throat. Among the other symptoms reported body ache was observed among $8(19.5 \%)$, dyspnea among $12(29.2 \%)$, headache among $6(14.6 \%)$, vomiting among $10(17.1 \%)$, diarrhea among $6(14.6 \%)$, dry cough among $12(29.2 \%)$, thoracic pain among $5(12.2 \%)$, febrile convulsions among $6(14.6 \%)$, respiratory distress among $26(54.6 \%)$, otitis among 2 (4.9\%), muscle pain among 15 (36.5\%), joint pain among $10(24.4 \%)$, and rhinorrhea among $22(53.6 \%)$.

The data related to these clinical symptoms and manifestations are graphically represented in Figure 1.

\section{DISCUSSION}

This article adds to the previous knowledge of clinical characteristics and outcomes of SARS-CoV-2 infection in pediatric age group. A small population of 97 COVID infected children in the Burdwan District of West Bengal, India. This study, therefore diagnoses the prevalence of positive cases in children with characteristics based on socio-demographic variables, co-morbidities, disease severity, clinical manifestations, laboratory parameters, CTScan, and oxygen support. The patients in our study showed higher rate of PICU admission per hospitalization (22.6\%), which may be due to a number of social factors negatively influencing the health status. Various reports suggest that the infection causes a milder impact on children, but our findings suggest that some children develop severe/critical disease and require immediate hospitalization and in some cases PICU admission, respiratory support, and mechanical ventilation. It has been found that these children show higher level of the inflammatory marker like CRP which probably lead to higher rate of ARDS. (Serum levels of different inflammatory cytokines linked to ARDS were,

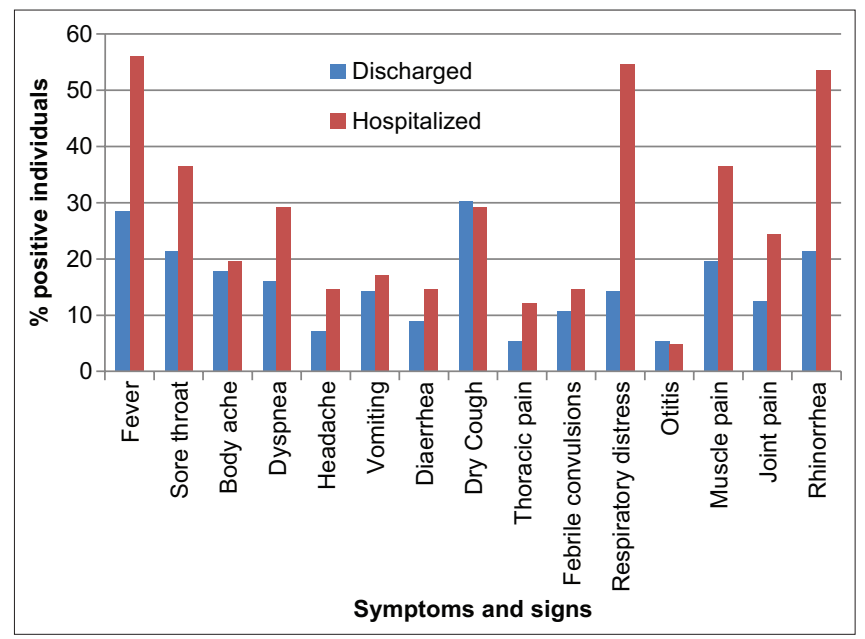

Figure 1: Schematic representation of different symptoms associated with the COVID positive children 


\begin{tabular}{|c|c|c|c|}
\hline Characteristics & Discharged at home $(n=56)$ & Hospitalized $(n=41)$ & $P$ value \\
\hline \multicolumn{4}{|l|}{ Age } \\
\hline$<1$ month & $4(7.3 \%)$ & $1(2.4 \%)$ & \multirow[t]{3}{*}{0.19} \\
\hline 1 month to 1 year & $8(14.2 \%)$ & $22(53.6 \%)$ & \\
\hline 1 year to 5 years & $44(78.5 \%)$ & $18(44 \%)$ & \\
\hline \multicolumn{4}{|l|}{ Sex } \\
\hline Male & $30(53.6 \%)$ & $17(41.4 \%)$ & \multirow[t]{2}{*}{0.73} \\
\hline Female & $26(46.4 \%)$ & $24(58.6 \%)$ & \\
\hline \multicolumn{4}{|l|}{ Ethnicity } \\
\hline Bengali & $51(91 \%)$ & $37(90.2 \%)$ & \multirow[t]{2}{*}{0.02} \\
\hline Non-Bengali & $5(9 \%)$ & $4(9.8 \%)$ & \\
\hline \multicolumn{4}{|l|}{ Family members infected } \\
\hline Yes & $33(58.9 \%)$ & $25(60.9 \%)$ & \multirow[t]{2}{*}{0.21} \\
\hline No & $23(41.1 \%)$ & $16(39.1 \%)$ & \\
\hline Ct value for COVID RT-PCR & Mean $=25.6+2.7$ & $23.8+3.2$ & 0.32 \\
\hline \multicolumn{4}{|l|}{ Disease severity } \\
\hline Asymptomatic & $36(64.3 \%)$ & 0 & \multirow[t]{5}{*}{0.003} \\
\hline Mild & $20(35.7 \%)$ & 0 & \\
\hline Moderate & 0 & $15(36.5 \%)$ & \\
\hline Severe & 0 & $12(29.2 \%)$ & \\
\hline Critical & 0 & $14(34.3 \%)$ & \\
\hline D-Dimer level (ug/ml) & Mean $=0.9+0.26$ & $0.83+0.34$ & 0.41 \\
\hline $\mathrm{CRP} \mathrm{mg} / \mathrm{dl}$ & Mean=1.8+1.5 & $6.3+2.6$ & 0.02 \\
\hline ESR mm/h & Mean $=26+2.5$ & $28+1.3$ & 0.22 \\
\hline \multicolumn{4}{|l|}{ Leukopenia } \\
\hline Yes & $11(19.6 \%)$ & $23(56.1 \%)$ & \multirow[t]{2}{*}{0.06} \\
\hline No & $45(80.4 \%)$ & $18(43.9 \%)$ & \\
\hline \multicolumn{4}{|l|}{ Lymphopenia } \\
\hline Yes & $7(12.5 \%)$ & $12(29.2 \%)$ & \multirow[t]{2}{*}{0.12} \\
\hline No & $49(87.5 \%)$ & $29(70.8 \%)$ & \\
\hline \multicolumn{4}{|l|}{ CT scan-infective changes } \\
\hline Yes & $6(10.7 \%)$ & $27(65.8 \%)$ & \multirow[t]{2}{*}{0.033} \\
\hline No & $50(89.3 \%)$ & $14(34.2 \%)$ & \\
\hline \multicolumn{4}{|l|}{ Respiratory support } \\
\hline Yes & 0 & $36(87.8 \%)$ & \multirow[t]{2}{*}{0.025} \\
\hline No & $56(100 \%)$ & $5(12.2 \%)$ & \\
\hline \multicolumn{4}{|l|}{ Mechanical ventilation } \\
\hline Yes & 0 & $17(41.4 \%)$ & \multirow[t]{2}{*}{0.41} \\
\hline No & $56(100 \%)$ & $24(58.6 \%)$ & \\
\hline \multicolumn{4}{|l|}{ Co-morbidities } \\
\hline Yes & $12(21.5 \%)$ & $13(31.7 \%)$ & \multirow[t]{2}{*}{0.81} \\
\hline No & $44(78.5 \%)$ & $28(68.3 \%)$ & \\
\hline \multicolumn{4}{|c|}{ Pediatric intensive care unit admission } \\
\hline Yes & 0 & $22(53.6 \%)$ & 0.04 \\
\hline No & $56(100 \%)$ & $19(46.4 \%)$ & \\
\hline Outcome & & & \\
\hline Cured & $53(94.6 \%)$ & $39(95.1 \%)$ & 0.43 \\
\hline Dead & $1(1.8 \%)$ & $2(4.9 \%)$ & \\
\hline
\end{tabular}

however, not estimated.) Different articles suggest that children co-morbidities have critical COVID-19 infection; but no such direct correlation could be found in our study. About $33.25 \%$ of our patients gave the history of coming in close proximity with an infected person. This high rate of community spread can be due to high population density in the region of our study, illiteracy and also failure to observe the requisite precautions of the disease.

A similar retrospective study ${ }^{8}$ was done in Morocco on 74 COVID affected children. They found that females were affected more by the infection than males like other studies. ${ }^{9}$ But in our study, no such sex predilection was noted (47 affected children were male and 50 were female - hospitalized and discharged taken together).

We found in our study that symptoms related to the respiratory and digestive systems were predominantly reported, similar to other studies. ${ }^{7}$ In our study, we found fever and cough was the commonest symptom in children. Different studies have also reported so ${ }^{10,11} 40-60 \%$ in children). In our study, we also found that diarrhea and vomiting was very commonly complained by the children which is similar to other studies. ${ }^{12}$ 
We also found leukopenia and not leukocytosis in 19.6\% of the discharged children and $56.1 \%$ of the hospitalized children which has also been reported in other studies. ${ }^{13}$ Lymphopenia was observed in $12.5 \%$ of the discharged children and $29.2 \%$ among those hospitalized, similar to a study done in Morocco on children who reported an incidence of $3 \%$ in their study population. ${ }^{8,14}$

A Chinese study ${ }^{15}$ had reported that infection in nearly $90 \%$ children is either asymptomatic or mild to moderate - severe infection being very less. Moroccan study also substantiated this finding. Even in our study, most children belonging to the discharged group were asymptomatic $(64.3 \%)$ and the rest $35.7 \%$ were mildly symptomatic. Among the hospitalized children $36.5 \%$ were moderately symptomatic, $29.2 \%$ presented severe complications, and $34.3 \%$ had a critical presentation.

Similarly, mortality is very much less in the children compared to adults. Only one child out of the 56 children discharged and two children out of those 41 children hospitalized died during the course of this study. This fact is also reported in different studies ${ }^{16,17}$

Hence, this study with a small population of children (97) during the time span of May 2020 to December 2020 developed mild COVID infection. This is in concordance with other studies done worldwide in this time span. The children were all discharged healthy and only a small percentage developed complication and only three died. Thus, based on our findings, it can be inferred that COVID 19 is a mild infection in children with very few life-threatening complications.

\section{Limitations of the study}

Sample size was not adequate as this retrospective study was conducted on a rapid emerging novel corona virus infection for a short period of time in a rural tertiary teaching hospital.

\section{CONCLUSION}

Here, we have presented a small retrospective observational study with a limited sample size attending a single, medical center, leading to type II statistical error, a major limitation to our study. However, as COVID-19 is a relatively new disease with limited number of data resources available from the infected pediatric population, our study will surely provide a better understanding of the infection.

\section{ACKNOWLEDGMENT}

We are grateful to the Principal, Dean and Medical Superintendent of Burdwan Medical College for allowing us to conduct the study. We are also thankful to all the staff of Microbiology and COVID laboratory for co-operating with us to carry out the study. Finally, we are very much grateful to all the participants of this study for their full hearted support and co-operations.

\section{REFERENCES}

1. Su L, Ma X, Yu H, Zhang Z, Bian P, Han Y, et al. The different clinical characteristics of corona virus disease cases between children and their families in China-the character of children with COVID-19. Emerg Microbes Infect. 2020;9(1):707-713. https://doi.org/10.1080/22221751.2020.1744483

2. Zheng F, Liao C, Fan QH, Chen HB, Zhao XG, Xie ZG, et al. Clinical characteristics of children with Coronavirus disease 2019 in Hubei, China. Curr Med Sci. 2020;40(2):275-280. https://doi.org/10.1007/s11596-020-2172-6

3. Wang D, Ju XL, Xie F, Lu Y, Li FY, Huang HH, et al. Clinical analysis of 31 cases of 2019 novel Coronavirus infection in children from six provinces (autonomous region) of Northern China. Zhonghua Er Ke Za Zhi. 2020;58(4):269-274. https://doi.org/10.3760/cma.j.cn112140-20200225-00138

4. Sun D, Li H, Lu X, Xiao H, Ren J, Zhang FR, et al. Clinical features of severe pediatric patients with coronavirus disease 2019 in Wuhan: A single center's observational study. World J Pediatr. 2020;16(3):251-259. https://doi.org/10.1007/s12519-020-00354-4

5. Shen K, Yang Y, Wang T, Zhao D, Jiang Y, Jin R, et al. Diagnosis, treatment, and prevention of 2019 novel Coronavirus infection in children: Experts' consensus statement. World J Pediatr. 2020;16(3):223-231.

https://doi.org/10.1007/s12519-020-00343-7

6. Bi Q, Wu Y, Mei S, Ye C, Zou X, Zhang Z, et al. Epidemiology and transmission of COVID-19 in 391 cases and 1286 of their close contacts in Shenzhen, China: A retrospective cohort study. Lancet Infect Dis. 2020;20(8):911-919.

https://doi.org/10.1016/S1473-3099(20)30287-5

7. Rodriguez-Morales AJ, Cardona-Ospina JA, Gutiérrez-Ocampo E, Villamizar-Peña R, Holguin-Rivera Y, Escalera-Antezana JP, et al. Clinical, laboratory and imaging features of COVID-19: A systematic review and meta-analysis. Travel Med Infect Dis. 2020;34:101623.

https://doi.org/10.1016/j.tmaid.2020.101623

8. El Fakiri K, Nassih H, Sab Ait I, Draiss G and Bouskraoui H. Epidemiology and clinical features of Coronavirus disease 2019 in Moroccan children. Indian Pediatr. 2020;57(9):808-810. https://doi.org/10.1007/s13312-020-1958-8

9. Tagarro A, Epalza C, Santos M, Sanz-Santaeufemia FJ, Otheo E, Moraleda C, et al. Screening and severity of Coronavirus disease 2019 (COVID-19) in children in Madrid, Spain. JAMA Pediatr. 2020;e201346.

https://doi.org/10.1001/jamapediatrics.2020.1346

10. Balla M, Merugu GP, Patel M, Koduri NM, Gayam V, Adapa S, et al. COVID-19, modern pandemic: A systematic review from front-line health care providers' perspective. J Clin Med Res. 2020;12(4):215-229. https://doi.org/10.14740/jocmr4142

11. Tian Y, Rong L, Nian W and He Y. Review article: Gastrointestinal features in COVID-19 and the possibility of faecal transmission. Aliment Pharmacol Ther. 2020;51(9):843-851.

https://doi.org/10.1111/apt.15731 
12. Meena J, Yadav J, Saini L, Yadav A, Kumar J. Clinical Features and Outcome of SARS-CoV-2 Infection in Children: A Systematic Review and Meta-analysis. Indian Pediatr. 2020 Sep 15;57(9):820-826. doi: 10.1007/s13312-020-1961-0. Epub 2020 Jun 24. PMID: 32583808; PMCID: PMC7498550.

13. Parohan M, Yaghoubi S and Seraj A. Liver injury is associated with severe Coronavirus disease (COVID-19) infection: A systematic review and meta-analysis of retrospective studies. Hepatol Res. 2020;50(8):924-935.

https://doi.org/10.1111/hepr.13510

14. Liu W, Zhang Q, Chen J, Xiang R, Song H, Shu S, et al. Detection of COVID-19 in children in early January 2020 in Wuhan, China. N Engl Med. 2020;382(14):1370-1371.

https://doi.org/10.1056/NEJMc2003717
15. Dong $\mathrm{Y}, \mathrm{Mo} X$, Hu Y, Qi X, Jiang F, Jiang Z, et al. Epidemiology of COVID-19 among children in China. Pediatrics. 2020;145(6):e20200702.

https://doi.org/10.1542/peds.2020-0702

16. Zimmermann $\mathrm{P}$ and Curtis $\mathrm{N}$. Coronavirus infections in children including COVID-19: An overview of the epidemiology, clinical features, diagnosis, treatment and prevention options in children. Pediatr Infect Dis J. 2020;39(5):355-368. https://doi.org/10.1097/INF.000000000000266

17. Chen N, Zhou M, Dong X, Qu J, Gong F, Han Y, et al. Epidemiological and clinical characteristics of 99 cases of 2019 novel corona virus pneumonia in Wuhan, China: A descriptive study. Lancet Lond Engl. 2020;395(10223):507-513. https://doi.org/10.1016/S0140-6736(20)30211-7

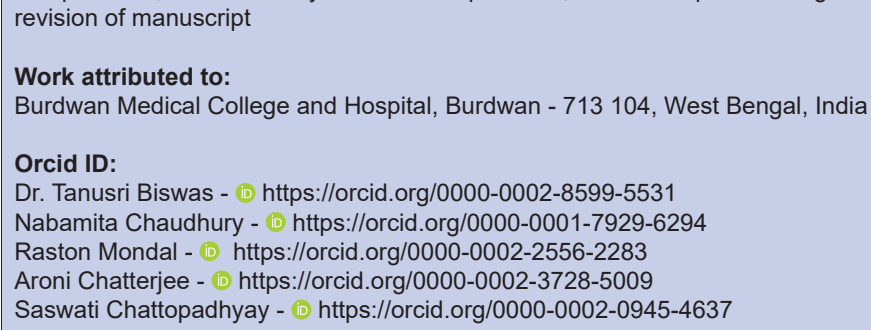

Source of Support: Nil, Conflict of Interest: None declared. 